\title{
Validation of resilience indicators by estimating genetic correlations among daughter groups and with yield responses to a heat wave and disturbances at herd level
}

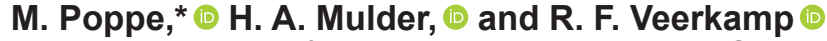 \\ Wageningen University \& Research, Animal Breeding and Genomics, PO Box 338, 6700 AH Wageningen, the Netherlands
}

\begin{abstract}
Resilient cows are minimally affected in their functioning by disturbances, and if affected, they quickly recover. Previously, the variance and autocorrelation of daily deviations from a lactation curve were proposed as resilience indicators. These traits were heritable and genetically associated with good health and longevity. However, it was unknown if selection for these indicators would lead to desired changes in the phenotype. The first aim of this study was to investigate if forward prediction of the resilience indicators in another environment was possible. Therefore, the resilience indicator records were split into 2 subsets, each containing half of the daughters of each sire, split within sire into cows that calved in early year-seasons and cows that calved in more recent year-seasons. Genetic correlations between the subsets were then estimated for each resilience indicator. The second aim was to estimate genetic correlations between the resilience indicators and traits describing production responses to actual disturbances. The disturbances were a heat wave in July 2015 and yield disturbances at herd level. The latter were selected by decreases in mean yield of all primiparous cows in a herd, indicating that a disturbance occurred. The data set used for calculation of the resilience indicators and the traits describing yield responses contained 62,932,794 daily milk yield records on 199,104 primiparous cows. Genetic correlations $\left(\mathrm{r}_{\mathrm{g}}\right)$ between recent and earlier daughter groups were 1 for both resilience indicators, which suggests that selection will result in changes in the phenotype in the next generation. Furthermore, low variance was genetically correlated with weak response in milk yield to both the
\end{abstract}

Received October 21, 2020.

Accepted March 1, 2021.

*Corresponding author: marieke.poppe@wur.nl heat wave and herd disturbances $\left(\mathrm{r}_{\mathrm{g}} 0.47\right.$ to 0.97$)$. Low autocorrelation was genetically correlated with reduced perturbation length and quick recovery after the heat wave and herd disturbances ( 0.28 to 0.97$)$. These results suggest that variance and autocorrelation cover different aspects of resilience, and should be combined in a resilience index. In conclusion, genetic selection for the resilience indicators will likely result in favorable changes in the traits themselves, and in response and recovery to actual disturbances, which confirms that they are useful resilience indicators.

Key words: resilience, response, recovery, validation

\section{INTRODUCTION}

Cows are regularly subject to environmental disturbances, such as pathogens, extreme weather, and changes in feed quality. Cows that are minimally affected in their functioning by disturbances, or that quickly recover, are called resilient (Colditz and Hine, 2016; Berghof et al., 2019b). Improvement of resilience is desirable, because resilient cows require less labor and treatments and have lower production losses than nonresilient cows (Berghof et al., 2019b).

To improve resilience through genetic selection, 2 resilience indicators have been developed (Poppe et al., 2020) based on Scheffer et al. (2018). The first is the natural log-transformed variance of deviations from an expected lactation curve (LnVar). Low LnVar was expected to indicate good resilience based on the hypothesis that cows with stable production are less affected in their functioning by disturbances than cows with variable production. The second resilience indicator is the lag-1 autocorrelation of yield deviations $\left(\mathbf{r}_{\text {auto }}\right)$. Low $\mathrm{r}_{\text {auto }}$ was expected to indicate good resilience based on the hypothesis that cows with low similarity between subsequent deviations do not have long periods of consecutive negative deviations and thus quickly recover from disturbances. Both resilience indicators showed genetic variation and were genetically associated with good udder health, little ketosis, 
and good longevity. Similar results have been shown for resilience indicators based on BW in chickens (Berghof et al., 2019a) and feed intake in pigs (Putz et al., 2019; Cheng et al., 2020).

Although LnVar and $r_{\text {auto }}$ are promising resilience indicators based on previous results, further validation is required. First, it should be investigated if selection for the resilience indicators based on a certain set of daughter phenotypes will result in lower realized LnVar and $r_{\text {auto }}$ in other daughters in other environments at other time points. When the environment of selection candidates differs from the environment in which the offspring perform, especially with respect to type and amount of environmental disturbances, limited phenotypic response to selection may be observed in the presence of genotype by environment interaction (Calus, 2006; Putz et al., 2019). For LnVar and $\mathrm{r}_{\text {auto }}$ it is unknown if they are genetically similar across years because of possible changes in environment, and thus if selection on these traits would be effective. An option for validation of EBV is forward prediction, which is commonly used for validating genomic EBV (Mäntysaari et al., 2010), and can also be used to predict phenotypes of second-crop daughters from EBV based on first-crop daughters (Ødegård et al., 2003).

Second, it should be validated if LnVar and $r_{\text {auto }}$ are related to strength of response and recovery to actual disturbances. The resilience indicators have only indirectly been shown to indicate resilience through genetic correlations with health traits and longevity, based on the hypothesis that resilient cows have fewer health problems and live longer than less resilient cows. However, health traits are mainly informative about incidence of disease, which is only one aspect of resilience and that only covers disease disturbances (Berghof et al., 2019b). Furthermore, longevity, although by some considered as a resultant of resilience, is affected largely by the culling decisions of farmers (van Pelt, 2017), which are not always related to resilience (Friggens et al., 2017). Therefore, it is important to investigate if low LnVar and $r_{\text {auto }}$ are also genetically associated with weaker response in milk yield and quicker recovery after a variety of actual disturbances.

The first aim of this study was to perform forward prediction by estimating for both LnVar and $\mathrm{r}_{\text {auto }}$ the genetic correlation between recent and earlier groups of daughters of each sire from nonoverlapping herd-yearseasons. The second aim was to estimate for both LnVar and $r_{\text {auto }}$ genetic correlations with traits describing production response to 2 disturbances selected based on available data: (1) a heat wave, and (2) an unknown disturbance at herd level.

\section{MATERIALS AND METHODS}

Genetic correlations between the same resilience indicators in earlier and more recent daughter groups in different herd-year-seasons of calving were estimated, as well as genetic correlations between the resilience indicators and traits describing yield responses to disturbances. The data used for these analyses will first be described. The calculation of resilience indicators and traits describing response to disturbances from these data will then be explained. Finally, the genetic analyses will be described.

\section{Data}

The original data set contained milk yield records obtained during single milk visits to automatic milking systems (AMS) and conventional milking systems. The data set was provided by Cooperation CRV and CRV BV (Arnhem, the Netherlands) and contained $1,782,373,113$ milk yield records on 1,120,550 Dutch cows. From these data, only data were selected from primiparous cows that were milked by AMS during their entire lactation, that were at least $87.5 \%$ Holstein Friesian, that were herd-book registered, that calved after $640 \mathrm{~d}$ of age, that had at least $50 \mathrm{~d}$ with milk yield records, that had no more than $5 \%$ of days with missing records, and that belonged to a herd-year-season of calving (HYS) class with at least 5 cows. Herdyear-seasons were based on 4 seasons (January-March, April-June, July-September, October-December). Data editing was the same as in Poppe et al. (2020) and was performed using the AWK programming language (Aho et al., 1988) and R ( $\mathrm{R}$ 3.2.2; R Project for Statistical Computing, Vienna, Austria).

Single milk yield records were first converted to daily records for each cow, by summing up the single milk yield records per day. The first milk yield record of each day was proportionally assigned to the current and the previous day, depending on the time between the current AMS visit and midnight and between the previous AMS visit and midnight. Milk yield records after 350 DIM were removed. In addition, daily milk yield records were removed if they deviated more than 6 standard deviations (SD) from a Wilmink curve fitted for individual cows (CRV, 2018) or if they were larger than $100 \mathrm{~kg}$. The limit of $6 \mathrm{SD}$ appeared mild enough upon visual inspection to preserve outliers that contain information about resilience. The resulting data set contained $62,932,794$ daily milk yield records on 199,104 cows in 2,733 herds. The resulting data set was used for computing (1) resilience indicators and 
average daily milk yield, and (2) traits describing yield response to 2 disturbances, which will be explained in the following paragraphs.

\section{Computing Resilience Indicators}

To calculate the resilience indicators, first for each cow a lactation curve was fitted to remove the effect of the shape of the lactation curve on the resilience indicators. Lactation curves were fitted using polynomial quantile regression with a quantile of 0.7 , because this method yielded the best resilience indicators in Poppe et al. (2020):

$$
y_{t}=\beta_{0}+\beta_{1} \times t+\beta_{2} \times t^{2}+\beta_{3} \times t^{3}+\beta_{4} \times t^{4}+\varepsilon,
$$

where $y_{t}$ is the observed milk yield on DIM $t ; t^{n}$ are DIM to the power of $n$, where $n$ is $1,2,3$, or $4 ; \beta_{n}$ are regression coefficients describing the relationships between $t^{n}$ and $y_{t}$; and $\varepsilon$ is the error term. The quantreg package (Koenker, 2018) and the poly function in $\mathrm{R}$ were used. Quantile regression (Koenker, 2005) with a quantile of 0.7 was used instead of classical regression to reduce the effect of decreases in milk yield due to disturbances on the expected milk yield. Consequently, the negative deviations became larger and probably more informative about resilience (Poppe et al., 2020, 2021). After fitting the lactation curves, for each cow the deviations from her curve were calculated as $y_{t}-\widehat{y_{t}}$. The resilience indicators were then computed by calculating the natural log-transformed variance (LnVar) and lag-1 autocorrelation $\left(\mathrm{r}_{\text {auto }}\right)$ of these deviations. High LnVar was expected to indicate poor resilience because decreases in milk yield due to disturbances will lead to increased variability in daily milk yield deviations. A high $\mathrm{r}_{\text {auto }}$ was expected to indicate poor resilience because decreases in milk yield due to disturbances will lead to increased similarity between deviations on subsequent days, especially when recovery is slow (Scheffer et al., 2018; Berghof et al., 2019b; Poppe et al., 2020). In addition to the resilience indicators, the average daily milk yield (ADMY) was calculated for each cow. The average daily milk yield was needed for adjusting genetic correlations between the resilience indicators and the traits describing yield responses to disturbances for milk yield level (see "Genetic Analysis"). Records on LnVar, $\mathrm{r}_{\text {auto }}$, and ADMY were removed if they deviated more than $4 \mathrm{SD}$ from the mean of all lactations. The resulting data set contained 199,074 records on LnVar, 198,908 records on $\mathrm{r}_{\text {auto }}$, and 199,085 records on ADMY.

\section{Preparation for Forward Prediction}

For the forward prediction, the data set containing LnVar and $r_{\text {auto }}$ was then split into 2 subsets. Only daughters from sires with at least 10 daughters were used. From each of these sires, the daughters were sorted based on their year-season of calving. For each sire, the daughter group was then split in 2 by the midpoint of the year-seasons of calving of the daughters. As a result, each sire had a more recent and an earlier calving daughter group. Averaged over all sires, the daughters in the more recent daughter groups calved $339 \mathrm{~d}$ later than the daughters in the accompanying earlier daughter groups. In addition, the daughter of each sire that calved earliest, calved on average $841 \mathrm{~d}$ earlier than the daughter that calved most recently. The more recent calving daughter groups of all sires were placed together in subset 1, and the earlier calving daughter groups of all sires were placed together in subset 2 . The resulting subsets contained cows with overlapping calving dates, because of differences in age of the sires and therefore differences in calving dates of the daughters: daughters of old and young sires with the same calving date could be placed in different daughter groups. However, the overlap is not a problem because for the forward prediction, the interest is in similarity between the resilience indicators of the 2 subsets within sire. Finally, subset 1 contained 93,517 records on LnVar and 93,436 records on $\mathrm{r}_{\text {auto }}$. Subset 2 contained 90,050 records on LnVar and 89,978 records on $\mathrm{r}_{\text {auto }}$. The subsets contained daughters of 1,761 sires.

\section{Computing Traits Describing Yield Response to Actual Disturbances}

The daily milk yield records were also used to compute traits describing the responses in milk yield of cows to 2 types of disturbances. The 2 types of disturbances were a heat wave and an unknown disturbance at herd level, based on a temporary decrease in mean herd yield. These 2 types of disturbances were selected based on availability of data on when the disturbances occurred and availability of sufficient cows with daily milk yield records. For each type of disturbance, several traits describing the response in milk yield, such as depth and length of the temporary yield decrease following the disturbance, were calculated for each cow. The determination of the 2 types of disturbances will first be described, followed by the calculation of the traits describing yield response to these disturbances (hereafter, "response traits"). 


\section{Heat Wave}

From the years with daily milk yield data (2011-2017), one severe heat wave was selected as a disturbance. For selecting a heat wave, mean daily temperature and mean daily relative humidity between May 2011 and September 2017 measured in a weather station in De Bilt were retrieved from the website of KNMI (KNMI, 2019). Because of the small size of the Netherlands, a heat wave detected in De Bilt was assumed to be present in the whole country. From the weather data, the temperature-humidity index (THI) was calculated as (National Research Council, 1971):

$\mathrm{THI}=(1.8 \times$ temperature +32$)-[(0.55-0.0055 \times$ humidity $) \times(1.8 \times$ temperature -26$)]$, where temperature was the mean daily temperature $\left({ }^{\circ} \mathrm{C}\right)$ and humidity was the mean daily relative humidity (\%). From the weather data, 15 dates were selected with a THI of at least 72 , because heat stress is assumed to start at a THI of 72 (Ravagnolo et al., 2000; Bohmanova et al., 2008). From these dates, the date was selected with the lowest mean THI across the 5 preceding days to ensure that the selected heat wave was sudden and could be considered a disturbance. This selected date was in 2011, and a limited number of cows with daily milk yield records were available at that time. Therefore, the date with the second lowest mean THI during the five preceding days was selected, which was July 1, 2015. The THI and the mean daily milk yield of the cows in our data set in the period after this date are shown in Figure 1. The figure shows that the heat wave lasted 4 $\mathrm{d}$ and that cows on average showed a decrease in milk yield during and after the heat wave, which confirmed that the selected heat wave was suitable for studying individual responses in milk yield. The mean daily temperature during the 4 -d heat wave was $25.3^{\circ} \mathrm{C}$, the minimum temperature was $15.8^{\circ} \mathrm{C}$, the maximum temperature was $33.1^{\circ} \mathrm{C}$, the mean daily relative humidity was $64.3 \%$, the minimum relative humidity measured was $30 \%$, the maximum relative humidity was $99 \%$, and the mean THI was 73.6. From the data set with daily milk yield records, cows were selected that had records from $10 \mathrm{~d}$ before the heat wave until $15 \mathrm{~d}$ after the heat wave, which were 28,105 cows.

\section{Disturbance at Herd Level}

For each herd in each year, a single date was selected where the mean milk yield of the cows temporarily decreased. In that case we can assume that a disturbance occurred at herd level, although the type of disturbance is unknown. Yield responses of individual cows to these disturbances (hereafter, "herd disturbances") can then be compared. First, for each date in the daily milk yield data set, the mean milk yield of the cows in each herd was calculated. Then, for each herd with at least half a year of daily milk yield data, dates were selected where the mean milk yield was lower than the mean of the $5 \mathrm{~d}$ before and the mean of the $5 \mathrm{~d}$ after, and the difference was larger than 3 times the SD of the $5 \mathrm{~d}$ before or the $5 \mathrm{~d}$ after. From these preselected dates, a single disturbance date was selected for each herd and each year,

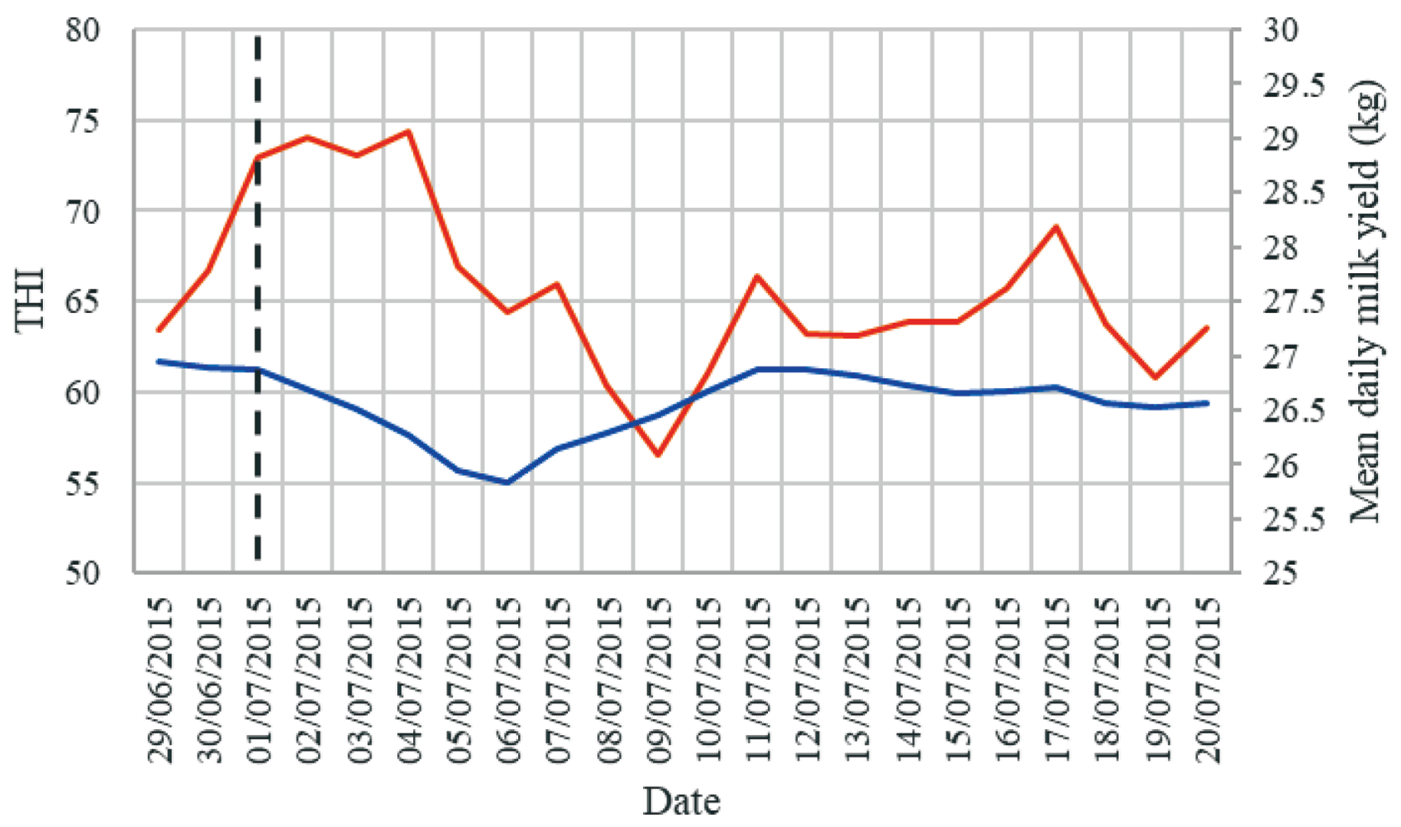

Figure 1. Temperature-humidity index (THI; orange) and mean daily milk yield of all cows in the data set (blue) in the period after the start of the selected heat wave (July 1, 2015; dashed line). Dates are in DD/MM/YYYY format. 
with the most extreme difference in milk yield with the $5 \mathrm{~d}$ before. These 8,905 final single disturbance dates per herd per year in 2,622 herds were used as disturbances in the further analyses. Figure 2 shows that the herd disturbances are spread evenly over all months of the year, with only somewhat increased occurrence in the summer months compared with the winter months. Therefore, the selected herd disturbances are certainly not all heat waves. For some cows, 2 herd disturbances occurred during their lactation, because their lactation was partly in 2 different years. For these cows, only the first disturbance was selected and used for calculation of the response traits. From the data set with daily milk yield records, cows were selected that had records from $10 \mathrm{~d}$ before the herd disturbance until $15 \mathrm{~d}$ after the herd disturbance, which were 129,722 cows.

\section{Response Traits}

Traits that describe their response to the heat wave and the herd disturbance were computed on individual cows. These traits were the depth and length of the temporary decrease in milk yield (hereafter referred to as "decrease"), the recovery time, the total amount of yield loss during the decrease, and the mean yield loss per day during the decrease. The start and the end of the decreases of each cow were determined based on deviations from a moving median. A moving median with a window of $21 \mathrm{~d}$ was fitted for each cow, which means that the expected milk yield on a day was the median of the $10 \mathrm{~d}$ before, the $10 \mathrm{~d}$ after, and the day itself, as in Poppe et al. (2020). The yield decrease of a cow was assumed to start as soon as the milk yield decreased below the moving median at or after the start of the heat wave, and at or before the date of the herd disturbance, because the herd disturbance must

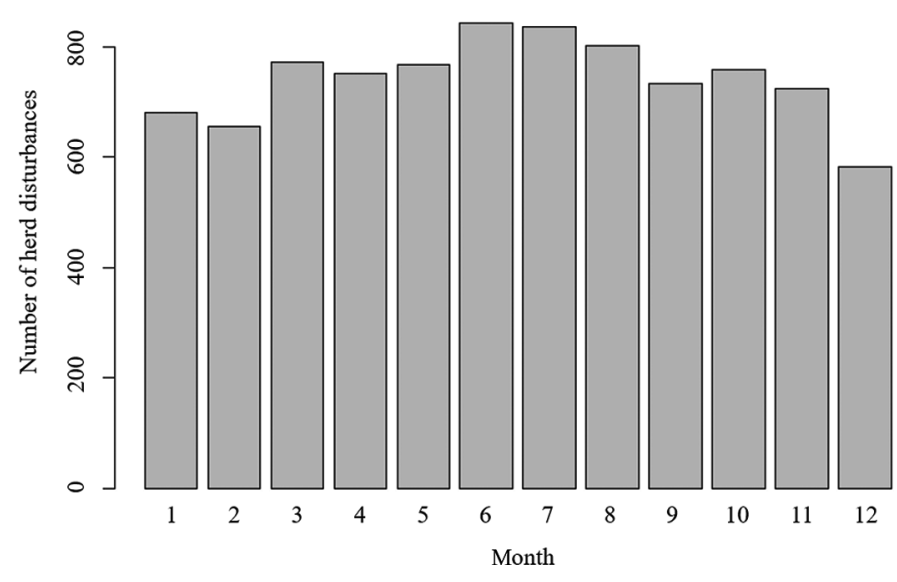

Figure 2. Number of herd disturbances selected in each month of the year. have occurred at or before the date that the cows in the herd decreased their milk yield. Some of the cows $(31,527)$ did not have a negative deviation on the herd disturbance date. These cows could be very resilient, but it is also possible that the herd disturbance did not act on them or they responded more quickly or slowly than their herdmates, causing their decrease to occur before or after the herd disturbance date. Because of the uncertainty about the exact moment of the herd disturbance and the response of these cows to the herd disturbance, it was decided to exclude them from the analyses. For the heat wave, cows that did not have a negative deviation during the heat wave were not removed, because they certainly experienced the heat wave. For both the heat wave and the herd disturbance, the decrease was assumed to end when the milk yield was at or above the moving median again.

The depth of the decrease was defined as the absolute difference between the lowest milk yield during the decrease and the milk yield at the day before the decrease. The length of the decrease was defined as the number of days between the start and end of the decrease. The recovery time was defined as the number of days between the day of the deepest yield during the decrease and the end of the decrease. The total yield loss was defined as the absolute sum of the negative deviations from the moving median during the decrease. The mean deviation per day was defined as the absolute mean of the negative deviations during the decrease. A resilient cow can be described as a cow with a shallow, short decrease with fast recovery and a small amount of yield lost in total and per day. For the heat wave, for cows that did not have a negative deviation within 4 $\mathrm{d}$ after the start of the heat wave, it was assumed that their milk yield did not respond to the heat wave, and the response traits were set to 0 , which means their response was as resilient as possible. The boundary of $4 \mathrm{~d}$ was based on Hayes et al. (2003), who showed that THI had a significant effect on milk yield up to $4 \mathrm{~d}$ later.

\section{Genetic Analyses}

First, we will describe the genetic analysis that investigated whether the resilience indicators were genetically the same trait in earlier and more recent daughter groups from different herd-year-season classes. After that, we will describe the genetic analysis that investigated whether low LnVar and $r_{\text {auto }}$ were related to shallow decreases in milk yield and quick recovery. Genetic analyses were performed using ASReml 4.1 (Gilmour et al., 2015). Variance parameters were kept in the theoretical parameter space, which means that genetic correlations could be 1 at maximum. 


\section{Genetic Correlations Between Earlier and More Recent Daughter Groups}

Genetic correlations were estimated between LnVar in subsets 1 and 2 , and between $r_{\text {auto }}$ in subsets 1 and 2 using a bivariate mixed sire model:

$$
\left[\begin{array}{l}
\mathbf{y}_{1} \\
\mathbf{y}_{2}
\end{array}\right]=\left[\begin{array}{cc}
\mathbf{X}_{1} & 0 \\
0 & \mathbf{X}_{2}
\end{array}\right]\left[\begin{array}{l}
\mathbf{b}_{1} \\
\mathbf{b}_{2}
\end{array}\right]+\left[\begin{array}{cc}
\mathbf{Z}_{1} & 0 \\
0 & \mathbf{Z}_{2}
\end{array}\right]\left[\begin{array}{l}
\mathbf{s}_{1} \\
\mathbf{s}_{2}
\end{array}\right]+\left[\begin{array}{l}
\mathbf{e}_{1} \\
\mathbf{e}_{2}
\end{array}\right]
$$

where $\mathbf{y}_{\mathrm{i}}$ was a vector with observations on LnVar or $\mathrm{r}_{\text {auto }}$ in subset $i$; $\mathbf{b}_{\mathrm{i}}$ was a vector with the fixed effects for LnVar or $\mathrm{r}_{\text {auto }}$ in subset $i$, which were HYS, age at first calving in months, and lactation length (remaining number of days after removing the first and last 10 DIM) in 7 classes, each containing a range of $40 \mathrm{~d}$ (e.g., 50-90 d, 91-130 d); $\mathbf{s}_{\mathrm{i}}$ was a vector with the additive genetic sire effects for LnVar or $\mathrm{r}_{\text {auto }}$ in subset $i$; and $\mathbf{e}_{\mathrm{i}}$ was a vector with the residuals for LnVar or $r_{\text {auto }}$ in subset $i$. $\mathbf{X}_{\mathrm{i}}$ and $\mathbf{Z}_{\mathrm{i}}$ were incidence matrices linking the records in $\mathbf{y}_{i}$ to the fixed effects and additive genetic effects, respectively. The additive genetic sire effects for all traits were assumed normally distributed with a mean of zero, a genetic sire variance of $\sigma_{s_{i}}^{2}$ for trait $i$ and a genetic covariance between traits of $\sigma_{s_{1} s_{2}}$ :

$$
\left[\begin{array}{l}
\mathbf{s}_{1} \\
\mathbf{s}_{2}
\end{array}\right] \sim N\left[\left(\begin{array}{l}
0 \\
0
\end{array}\right), \mathrm{A} \otimes\left(\begin{array}{cc}
\sigma_{s_{1}}^{2} & \sigma_{s_{1} s_{2}} \\
\sigma_{s_{1} s_{2}} & \sigma_{s_{2}}^{2}
\end{array}\right)\right],
$$

where $\mathbf{A}$ is the additive genetic relationship matrix containing genetic relationships among sires. Five generations of ancestors were included. The residuals were assumed normally distributed as well, with a mean of zero, a residual variance of $\sigma_{e_{i}}^{2}$ for trait $i$, and a residual covariance between traits of 0 :

$$
\left[\begin{array}{l}
\mathbf{e}_{1} \\
\mathbf{e}_{2}
\end{array}\right] \sim N\left[\left(\begin{array}{l}
0 \\
0
\end{array}\right), \mathbf{I} \otimes\left(\begin{array}{cc}
\sigma_{e_{1}}^{2} & 0 \\
0 & \sigma_{e_{2}}^{2}
\end{array}\right)\right],
$$

where $\mathbf{I}$ is an identity matrix. A residual covariance of 0 was assumed because records were always on different cows. A sire model was used because the sires formed the genetic link between the 2 subsets. In addition to the genetic correlations, additive genetic variance was calculated for each trait in each subset as $\sigma_{a}^{2}=4 \sigma_{s}^{2}$, and phenotypic variance was calculated as $\sigma_{s}^{2}+\sigma_{e}^{2}$.

\section{Variance Components of the Response Traits}

Univariate mixed sire-maternal grandsire (mgs) models were first used to investigate if the response traits of the heat wave and the herd disturbance showed genetic variation:

$$
\mathbf{y}=\mathbf{X} \mathbf{b}+\left(\mathbf{Z}_{1} \mathbf{s}+1 / 2 \mathbf{Z}_{2} \mathbf{s}\right)+\mathbf{e}
$$

where $\mathbf{y}$ was a vector with observations on the response trait; b was a vector with covariates and fixed effects, which were DIM at the start of the decrease, DIM ${ }^{2}$, $\mathrm{DIM}^{3}$, herd-year of calving, and year-season of calving (year-season only for response traits to the herd disturbance because of significance); $\mathbf{s}$ was a vector containing the additive genetic sire effects (linked to the phenotypes by incidence matrix $\mathbf{Z}_{1}$ ) overlaid by one-half of the mgs effects (linked by incidence matrix $\mathbf{Z}_{2}$ ), $\mathbf{s} \sim N\left(0, \mathbf{A} \sigma_{s}^{2}\right)$, where $\sigma_{s}^{2}$ is the sire variance; and e was a vector with the residuals, $\mathbf{e} \sim N\left(0, \mathbf{I} \sigma_{e}^{2}\right)$. The used pedigree contained 5 generations of ancestors. Additive genetic variance was calculated as $\sigma_{a}^{2}=4 \sigma_{s}^{2}$, and phenotypic variance was calculated as $\sigma_{p}^{2}=1.25 \sigma_{s}^{2}+\sigma_{e}^{2}$.

\section{Genetic Correlations Between Resilience Indicators, Response Traits, and ADMY}

Genetic correlations between the resilience indicators and the response traits, among response traits, and among resilience indicators and ADMY were estimated using bivariate mixed sire-mgs models. The fixed effects were as described in the univariate analysis of the response traits, or in the bivariate analysis of the resilience indicators. The following assumptions were made about the sire effects and residuals:

$$
\begin{gathered}
{\left[\begin{array}{l}
\mathbf{s}_{1} \\
\mathbf{s}_{2}
\end{array}\right] \sim N\left[\left(\begin{array}{l}
0 \\
0
\end{array}\right), \mathbf{A} \otimes\left(\begin{array}{cc}
\sigma_{s_{1}}^{2} & \sigma_{s_{1} s_{2}} \\
\sigma_{s_{1} s_{2}} & \sigma_{s_{2}}^{2}
\end{array}\right)\right],} \\
{\left[\begin{array}{l}
\mathbf{e}_{1} \\
\mathbf{e}_{2}
\end{array}\right] \sim N\left[\left(\begin{array}{l}
0 \\
0
\end{array}\right), \mathbf{I} \otimes\left(\begin{array}{cc}
\sigma_{e_{1}}^{2} & \sigma_{e_{1} e_{2}} \\
\sigma_{e_{1} e_{2}} & \sigma_{e_{2}}^{2}
\end{array}\right)\right],}
\end{gathered}
$$

where $\sigma_{s_{i}}^{2}$ is the sire variance for trait $i, \sigma_{s_{1} s_{2}}$ is the sire covariance between the traits, $\sigma_{e_{i}}^{2}$ is the residual variance for trait $i$, and $\sigma_{e_{1} e_{2}}$ is the residual covariance be- 
Table 1. The number of records used for estimating genetic correlations between response traits and resilience indicators LnVar (natural log-transformed variance of milk yield deviations), $r_{\text {auto }}$ (lag-1 autocorrelation of milk yield deviations), and average daily milk yield $(\mathrm{ADMY})$ in $\mathrm{kg}$

\begin{tabular}{lcccc}
\hline Disturbance & $\begin{array}{c}\text { Response } \\
\text { trait }\end{array}$ & LnVar & $\mathrm{r}_{\text {auto }}$ & ADMY \\
\hline Heat wave & 22,282 & 97,349 & 97,235 & 97,388 \\
Herd disturbance & 70,584 & 79,280 & 79,169 & 79,294 \\
\hline
\end{tabular}

tween the traits. To ensure that there was no direct relation between the response traits and the resilience indicators within cows, for cows with data during the disturbance and therefore with a response trait to a disturbance, their record for the resilience indicators was set to missing and the residual covariance between response traits and resilience indicators was set to 0 . Similarly, for the genetic correlations between the response traits to the heat wave and the same response traits to the herd disturbance, the response traits to the herd disturbance were set to missing if the herd disturbance was between June 30 and July 11, 2015 (during the studied heat wave; 44 herd disturbances). Herdyear-season of calving classes, herd-year classes, and sires were removed that contained fewer than 5 records on the resilience indicators or the response traits. The final number of records used for estimating genetic correlations between the resilience indicators and the response traits are shown in Table 1.

Average daily milk yield had strong genetic correlations with both LnVar and some of the response traits. Therefore, it was difficult to determine if there was any association between LnVar and the response traits that could not be explained by ADMY. To investigate the association between LnVar and the response traits, independent of ADMY, partial genetic correlations between the resilience indicators and the response traits were computed, adjusted for genetic correlations with $\operatorname{ADMY}\left(r_{x y, z}\right)$. The following formula was used (Poppe et al., 2020):

$$
r_{x y, z}=\frac{r_{x y}-r_{x z} r_{y z}}{\sqrt{1-r_{x z}^{2}} \sqrt{1-r_{y z}^{2}}}
$$

where $x$ is LnVar, $y$ is the response trait, and $z$ is ADMY. The genetic correlations between LnVar or ADMY and the response traits, and between LnVar and ADMY were taken from the bivariate analyses. No standard error could be computed for the partial genetic correlations.

\section{RESULTS}

\section{Forward Prediction of Resilience Indicators}

The 2 subsets with recent and earlier calving daughter groups showed similar sire and error variances and heritabilities (Table 2). The sire variances were 0.01 in both subsets for LnVar, and 0.0005 in both subsets for $\mathrm{r}_{\text {auto. }}$. The error variances were 0.24 and 0.25 for LnVar, and 0.028 in both subsets for $r_{\text {auto }}$. The heritabilities were 0.18 and 0.17 for LnVar, and 0.07 and 0.06 for $\mathrm{r}_{\text {auto }}$. The genetic correlations between recent and earlier daughter groups were 1.00 for both LnVar and $r_{\text {auto. }}$.

\section{Descriptive Statistics of Response Traits}

Milk yield decreased on average by $2.37 \mathrm{~kg}$ in response to the heat wave and by $4.73 \mathrm{~kg}$ in response to the herd disturbance (Table 3). The decrease in milk yield lasted on average $2.99 \mathrm{~d}$ after the heat wave and $3.44 \mathrm{~d}$ after the herd disturbance. The time between the lowest yield and the time of recovery was on average $2.02 \mathrm{~d}$ after the heat wave and $2.27 \mathrm{~d}$ after the herd disturbance. The minimum duration of the decrease was $0 \mathrm{~d}$ for the heat wave, which was for cows that did not show a decrease. The minimum duration of the decrease was $1 \mathrm{~d}$ for the herd disturbance, because only cows were included that showed a decrease in milk yield on the date of their herd disturbance. For both the heat

Table 2. Sire variance $\left(\sigma_{s}^{2}\right)$, error variance $\left(\sigma_{e}^{2}\right)$, heritability $\left(\mathrm{h}^{2}\right)$, and genetic correlation $\left(\mathrm{r}_{\mathrm{g}}\right)$ between subsets from the bivariate analysis of the resilience indicators LnVar (natural log-transformed variance of milk yield deviations) and $r_{\text {auto }}$ (lag-1 autocorrelation of milk yield deviations) in 2 subsets of cows, one containing the daughters of each sire that calved more recently and the other containing the daughters that calved earlier ${ }^{1}$

\begin{tabular}{|c|c|c|c|c|c|}
\hline Trait & Subset & $\sigma_{s}^{2}$ & $\sigma_{e}^{2}$ & $h^{2}$ & $\mathrm{r}_{\mathrm{g}}$ \\
\hline \multirow[t]{2}{*}{ LnVar } & 1 & $0.011(0.00094)$ & $0.24(0.0013)$ & $0.18(0.01)$ & \multirow[t]{2}{*}{$1.00^{2}$} \\
\hline & 2 & $0.010(0.00093)$ & $0.25(0.0014)$ & $0.17(0.01)$ & \\
\hline \multirow{2}{*}{$\mathrm{r}_{\text {auto }}$} & 1 & $0.00053(0.000062)$ & $0.028(0.00015)$ & $0.074(0.0084)$ & \multirow{2}{*}{$1.00^{2}$} \\
\hline & 2 & $0.00045(0.000054)$ & $0.028(0.00015)$ & $0.064(0.0076)$ & \\
\hline
\end{tabular}

${ }^{1} \mathrm{SE}$ in parentheses.

${ }^{2} \mathrm{SE}$ was not estimable. 
Table 3. Descriptive statistics of the response traits describing a temporary decrease in milk yield of individual cows in response to a heat wave and a disturbance at herd level

\begin{tabular}{llcccc}
\hline Disturbance & Response trait & Mean & Minimum & Maximum & SD \\
\hline Heat wave & Decrease depth (kg) & 2.37 & -14.48 & 26.79 & 3.13 \\
& Decrease length (d) & 2.99 & 0 & 10 & 2.48 \\
& Recovery time (d) & 2.02 & 0 & 10 & 1.65 \\
& Total yield loss (kg) & 5.28 & 0.00 & 86.01 & 7.30 \\
Herd disturbance & Mean yield loss per day (kg) & 1.41 & 0.00 & 20.83 & 1.50 \\
& Decrease depth (kg) & 4.73 & 0.00 & 29.01 & 3.96 \\
& Decrease length (d) & 3.44 & 1 & 10 & 2.14 \\
& Recovery time (d) & 2.27 & 1 & 10 & 1.55 \\
& Total yield loss (kg) & 7.20 & 0.00 & 86.83 & 7.36 \\
& Mean yield loss per day (kg) & 2.24 & 0.00 & 22.41 & 2.28 \\
\hline
\end{tabular}

wave and the herd disturbance the maximum duration was $10 \mathrm{~d}$. The mean deviation from the expected yield per day during the decrease was $1.41 \mathrm{~kg}$ after the heat wave and $2.24 \mathrm{~kg}$ after the herd disturbance. The total yield loss during the decrease in milk yield was on average $5.28 \mathrm{~kg}$ after the heat wave and $7.20 \mathrm{~kg}$ after the herd disturbance.

\section{Genetic Variances and Heritabilities of Response Traits and Genetic Correlations Between Them}

Heritabilities of the response traits to the heat wave ranged between 0.01 for mean yield loss per day and 0.05 for total yield loss during the decrease (Table 4). The heritabilities and sire and error variances were all significantly different from 0 . Heritabilities of the response traits to the herd disturbance ranged between 0.001 for decrease length and 0.02 for the decrease depth (Table 4). The heritabilities and sire and error variances were significantly different from 0 , except for the sire variance and heritability of decrease length and recovery time.

All variables describing response to the heat wave were highly genetically correlated with each other, with genetic correlations from 0.77 between recovery time and mean yield loss per day, up to 1.00 between decrease length and recovery time and decrease depth and recovery time (Table 5). The variables describing response to the herd disturbance were also positively correlated with each other, with genetic correlations ranging from 0.04 between decrease length and mean yield loss per day to 1.00 between decrease depth and mean yield loss per day.

The response traits to the heat wave were in most cases positively genetically correlated with the corresponding response traits to the herd disturbance (Table 6 ). The genetic correlations ranged from -0.03 for recovery time to 0.61 for mean yield loss per day. In summary, different response traits within the same disturbance were positively, and often strongly, genetically correlated with each other, and the same response traits to different disturbances were also mostly positively genetically correlated.

\section{Genetic Correlations Between Resilience Indicators and Response Traits}

The genetic correlations between resilience indicators and response traits after the heat wave ranged between -0.06 and 0.71 . The highest values were observed for LnVar, where correlations with decrease depth, total yield loss, and mean yield loss per day ranged between

Table 4. Sire variance $\left(\sigma_{s}^{2}\right)$, error variance $\left(\sigma_{e}^{2}\right)$, and heritability $\left(\mathrm{h}^{2}\right)$ from univariate analysis of traits describing the response in milk yield to the heat wave of July 1,2015 , and to an unknown disturbance at herd level ${ }^{1}$

\begin{tabular}{|c|c|c|c|c|}
\hline Disturbance & Response trait & $\sigma_{s}^{2}$ & $\sigma_{e}^{2}$ & $h^{2}$ \\
\hline \multirow[t]{4}{*}{ Heat wave } & Decrease depth $(\mathrm{kg})$ & $0.034(0.014)$ & $8.53(0.085)$ & $0.016(0.0063)$ \\
\hline & Decrease length (d) & $0.036(0.011)$ & $5.31(0.053)$ & $0.027(0.0081)$ \\
\hline & Total yield loss (kg) & $0.57(0.14)$ & $45.17(0.45)$ & $0.050(0.012)$ \\
\hline & Mean yield loss per day $(\mathrm{kg})$ & $0.0060(0.0028)$ & $1.95(0.020)$ & $0.012(0.0058)$ \\
\hline \multirow{3}{*}{ Herd disturbance } & Decrease depth (kg) & $0.050(0.010)$ & $9.87(0.055)$ & $0.020(0.0040)$ \\
\hline & Decrease length (d) & $0.0011(0.0012)$ & $4.20(0.024)$ & $0.0010(0.0011)$ \\
\hline & Mean yield loss per day $(\mathrm{kg})$ & $0.012(0.0028)$ & $3.54(0.020)$ & $0.013(0.0031)$ \\
\hline
\end{tabular}

${ }^{1} \mathrm{SE}$ in parentheses. 
Table 5. Genetic correlations among different traits describing yield response to the same disturbance (heat wave of July 1, 2015, or an unknown disturbance at herd level) ${ }^{1}$

\begin{tabular}{|c|c|c|c|c|c|}
\hline Disturbance & Response trait & $\begin{array}{l}\text { Decrease } \\
\text { length (d) }\end{array}$ & $\begin{array}{l}\text { Recovery } \\
\text { time (d) }\end{array}$ & $\begin{array}{l}\text { Total yield } \\
\text { loss (kg) }\end{array}$ & $\begin{array}{l}\text { Mean yield loss } \\
\text { per day }(\mathrm{kg})\end{array}$ \\
\hline Heat wave & $\begin{array}{l}\text { Decrease depth }(\mathrm{kg}) \\
\text { Decrease length }(\mathrm{d}) \\
\text { Recovery time }(\mathrm{d}) \\
\text { Total yield loss }(\mathrm{kg})\end{array}$ & $0.99(0.057)$ & $\begin{array}{l}1.00(0.088) \\
1.00(0.026)\end{array}$ & $\begin{array}{l}0.99(0.027) \\
0.95(0.028) \\
0.93(0.053)\end{array}$ & $\begin{array}{l}0.99(0.05) \\
0.85(0.11) \\
0.77(0.17) \\
0.95(0.059)\end{array}$ \\
\hline Herd disturbance & $\begin{array}{l}\text { Decrease depth }(\mathrm{kg}) \\
\text { Decrease length }(\mathrm{d}) \\
\text { Recovery time }(\mathrm{d}) \\
\text { Total yield loss }(\mathrm{kg})\end{array}$ & $0.053(0.35)$ & $\begin{array}{l}0.16(0.26) \\
0.95(0.22)\end{array}$ & $\begin{array}{l}0.99(0.019) \\
0.17(0.35) \\
0.23(0.26)\end{array}$ & $\begin{array}{l}1.00(0.025) \\
0.036(0.37) \\
0.10(0.28) \\
0.99(0.035)\end{array}$ \\
\hline
\end{tabular}

${ }^{1} \mathrm{SE}$ in parentheses.

0.39 and 0.71 (Table 7). These genetic correlations suggest that daughters of sires with high EBV for LnVar tended to have deeper yield decreases after the heat wave, a larger total yield loss, and a larger mean yield loss per day than daughters of sires with low EBV for LnVar. Genetic correlations between LnVar and decrease length and recovery time upon the heat wave were weak (0.15 and 0.07). Average daily milk yield, which had a strong genetic correlation with LnVar $(0.76$ in this data set, $\mathrm{SE}=0.032)$, showed similar genetic correlations with the response traits of the heat wave as LnVar (0.09 to 0.59). Therefore, the partial genetic correlations between LnVar and the response traits, adjusted for genetic correlations with ADMY are needed to interpret the association between variability in milk yield and response to the heat wave, independent of milk yield level. The partial genetic correlations suggest that among cows with the same genetic milk yield level, a high LnVar was still genetically associated with large decreases in milk yield and a high mean yield loss per day, although the partial genetic correlations were weaker than the original correlations ( 0.21 and 0.49 ; Table 7). The partial genetic correlations between LnVar and total yield loss, decrease length and recovery time were negligible (0.00 to 0.06 ). Genetic correlations between $r_{\text {auto }}$ and the response traits to the heat wave ranged from -0.05 for mean yield loss per day to 0.34 for decrease length. These genetic correlations indicate that daughters of sires with high EBV for $r_{\text {auto }}$ tended to have deeper and longer yield decreases than daughters of sires with low EBV for $r_{\text {auto }}$.

In comparison with the genetic correlations after the heat wave, even larger genetic correlations were found after the herd disturbances between LnVar and decrease depth, total yield loss, and mean yield loss per day, ranging from 0.90 to 0.97 (Table 7). Genetic correlations between LnVar and decrease length and recovery time upon the herd disturbances remained weak $(-0.001$ and 0.06$)$. Average daily milk yield again had a strong genetic correlation with LnVar (0.77 in this data set, $\mathrm{SE}=0.030$ ), and showed similar genetic correlations with decrease depth, total yield loss, and mean yield loss per day compared with LnVar (0.88 to 0.91), but the genetic correlations with decrease length and recovery time were slightly stronger $(0.15$ and 0.14$)$. The partial genetic correlations of LnVar with depth of the decrease and total yield loss were weaker than the original correlations (0.82 and 0.74$)$, but the partial genetic correlation with mean yield loss per day was stronger $(0.99$; Table 7$)$. The partial genetic correlations of LnVar with decrease length and recovery time were negative but weak $(-0.18$ and -0.08$)$. Genetic correlations between $r_{\text {auto }}$ and the response traits of the herd disturbance ranged between -0.35 for mean yield loss per day and 0.97 for decrease length. These genetic correlations indicate that daughters of sires with high EBV for $\mathrm{r}_{\text {auto }}$ tended to have longer decreases and slower recovery, but a smaller yield loss per day than daughters of sires with low EBV for $r_{\text {auto }}$. The genetic correlations with decrease depth $(-0.13)$ and total yield loss $(-0.01)$ were weak. In summary, daughters of sires with high EBV for LnVar seemed to have more extreme decreases in milk yield and a greater yield loss upon both the heat wave and the herd disturbance than daughters of sires with low EBV for LnVar, even when adjusted for ADMY. Daughters of sires with high EBV for $r_{\text {auto }}$ seemed to have slower recovery from both the

Table 6. Genetic correlations $\left(\mathrm{r}_{\mathrm{g}}\right)$ between the same traits describing yield response to two different disturbances: the heat wave of the July 1,2015 , and an unknown disturbance at herd level ${ }^{1}$

\begin{tabular}{lc}
\hline Item & $\mathrm{r}_{\mathrm{g}}$ \\
\hline Decrease depth $(\mathrm{kg})$ & $0.26(0.20)$ \\
Decrease length (d) & $0.46(0.34)$ \\
Recovery time (d) & $-0.029(0.34)$ \\
Total yield loss (kg) & $0.39(0.16)$ \\
Mean yield loss per day $(\mathrm{kg})$ & $0.61(0.20)$ \\
\hline
\end{tabular}

${ }^{1} \mathrm{SE}$ in parentheses. 
Table 7. Genetic correlations between traits describing the response in milk yield to the heat wave of July 1, 2015, and to an unknown disturbance at herd level, and natural log-transformed variance of milk yield deviations (LnVar), lag-1 autocorrelation of milk yield deviations $\left(\mathrm{r}_{\text {auto }}\right)$, and average daily milk yield $(\mathrm{ADMY})^{1}$

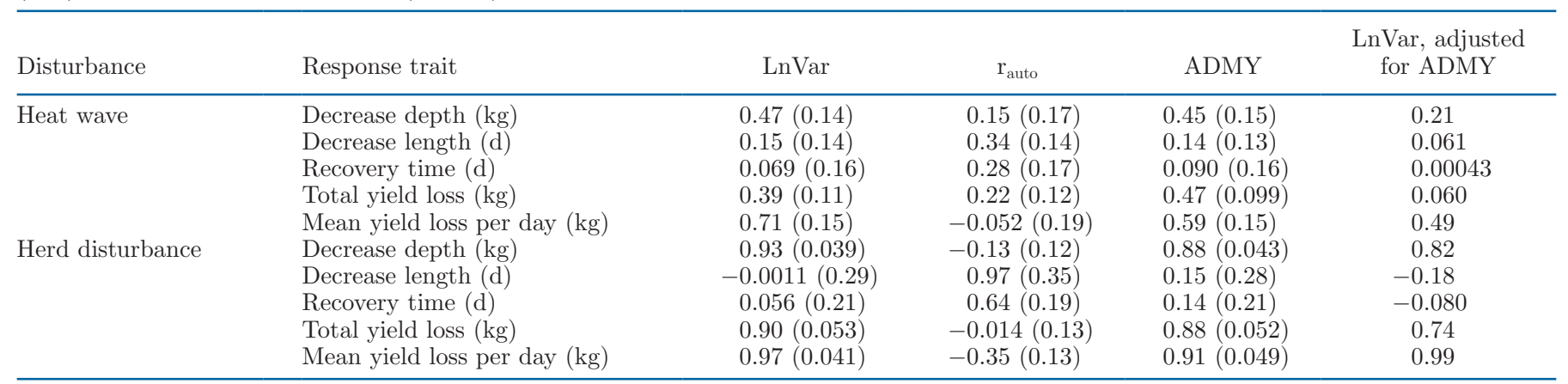

${ }^{1} \mathrm{SE}$ in parentheses. Partial correlations between LnVar and the response traits, adjusted for genetic correlations with ADMY, are also given.

heat wave and the herd disturbances than daughters of sires with low EBV for $\mathrm{r}_{\text {auto }}$.

\section{DISCUSSION}

The traits LnVar and $r_{\text {auto }}$ have been developed to assist in genetic selection for improved resilience. Low LnVar and low $r_{\text {auto }}$ are hypothesized to indicate good resilience, because low LnVar indicates low variability in milk yield deviations from an expected curve, and low $r_{\text {auto }}$ indicates weak similarity between subsequent milk yield deviations. Results of this study show that both LnVar and $r_{\text {auto }}$ were genetically the same traits in a more recent and an early group of daughters of sires. This indicates that these traits are similar over time and have predictive value across herd-year-seasons. Furthermore, low LnVar was genetically correlated with good resilience measured as a weak response in milk yield to a heat wave and an unknown disturbance at herd level. Low $\mathrm{r}_{\text {auto }}$ was genetically correlated with quick recovery from a heat wave and herd disturbances, but with a larger production loss per day upon herd disturbances. We will first discuss in more detail the association between resilience indicators in different daughter groups. We will then discuss the association between the resilience indicators and production response to different disturbances.

The unity genetic correlations between the subsets with earlier and more recent daughters of each sire for each resilience indicator, showed that LnVar and $r_{\text {auto }}$ were genetically the same at different time points and in different herd-year-season classes. Although a heritability estimate above zero already indicates that animals across environments have a genetic covariance, this validation is an important outcome for such an environmentally sensitive trait, because it further validates the usefulness for forward prediction under other environmental circumstances. Similar results have been found in Norwegian Red cattle for prediction of performance for clinical mastitis of second-crop daughters using predicted transmitting abilities based on clinical mastitis records of first-crop daughters (Ødegård et al., 2003). An explanation for the unity genetic correlation of resilience indicators between the 2 daughter groups and heritability above zero, is that the range of disturbances determining LnVar and $r_{\text {auto }}$ is probably similar between time points and between herd-year-seasons. Therefore, genetic improvement of LnVar and $r_{\text {auto }}$ in future generations, which are expected to have a similar range of disturbances, will likely be observed upon selection.

The resilience indicators LnVar and $r_{\text {auto }}$ were based on the theory that fluctuations in longitudinal data are informative about resilience of systems, because they describe response and recovery to small, naturally occurring disturbances (Scheffer, 2009; Scheffer et al., 2018). Previous studies, also on similar traits in pigs and poultry, have confirmed this indirectly because of favorable genetic correlations with health and longevity traits (Berghof et al., 2019a; Putz et al., 2019; Poppe et al., 2020). However, none of these studies directly investigated if the resilience indicators were related to strength of response and recovery to actual disturbances. In this study, genetic correlations between the resilience indicators and the response traits, which were mostly moderate to strong, confirm that LnVar and $r_{\text {auto }}$ are related to direct response of milk yield to disturbances. LnVar seems mainly informative about the extent to which production is affected by disturbances. In fact, the genetic correlations with decrease depth, total yield loss, and mean yield loss per day after the herd disturbance (Table 7) were close to unity and remained strong when adjusted for milk yield level. This confirms that the simple trait LnVar effectively captures the extent of response in milk yield to all kinds of disturbances. Although LnVar was not related to the length of the yield 
decrease and recovery time, $\mathrm{r}_{\text {auto }}$ showed moderate to strong genetic correlations with these traits, and therefore seems mainly informative about speed of recovery, and less to the extent of yield loss upon disturbances. Further research is needed to determine if these traits are informative about not only production response to disturbances, but also response in other elements of functioning (Colditz and Hine, 2016), such as behavior. Furthermore, genetic associations between the current resilience indicators and response to additional specific disturbances, such as mastitis as studied by I. Adriaens (KU Leuven, Geel, Belgium), I. van den Brulle (Ghent University, Merelbeke, Belgium), and B. Aernouts (KU Leuven, Geel, Belgium; unpublished data), should be studied. Moreover, it would be interesting to investigate if similar resilience indicators based on test-day milk yield data or from conventional milking systems would yield similar results. If so, the number of records on resilience indicators for genetic evaluation could be increased substantially. Nevertheless, our findings are a first important confirmation that LnVar and $r_{\text {auto }}$ based on daily milk yield data from AMS are informative about resilience to general disturbances and a heat wave in particular.

Associations between response traits and the resilience indicators were mostly in the same direction for both the heat wave and the herd disturbance. Therefore, it is important to investigate to what extent the herd disturbances and the heat wave overlap and have the same underlying effect. Only 44 out of 8,905 herd disturbances occurred around the date of the studied heat wave, which shows that there is limited direct overlap. These 44 herd disturbances were excluded when estimating the genetic correlations between the response traits to the 2 disturbances (Table 6). These were different from zero, which may suggest that the remaining herd disturbances partly consist of other heat waves. Nevertheless, a substantial number of the herd disturbances occurred in winter and were thus certainly not heat waves (Figure 1). Therefore, a common genetic basis for different types of disturbances may exist, and common mechanisms may act on different disturbances in the body (Colditz and Hine, 2016). In summary, we expect the herd disturbances to represent a broad range of disturbances, heat waves being only one of them.

The resilience indicators LnVar and $\mathrm{r}_{\mathrm{auto}}$ were designed without knowing if and when disturbances occurred, whereas the response traits certainly contain information about resilience. Therefore, the question may be raised if we should use the response traits directly to breed for improved resilience. However, this is not recommended for several reasons. The first reason is that the heritabilities of most response traits (0.001 to 0.05$)$ were considerably lower than the heritabilities of LnVar and $\mathrm{r}_{\text {auto }}(0.21$ and 0.08 , respectively; Poppe et al., 2020). The low heritabilities of the response traits are probably due to describing response to only a single disturbance per cow. A disturbance related to a single event is more prone to random noise, and consequentially leads to increased error variance. LnVar and $r_{\text {auto }}$ summarize response to all disturbances throughout the entire lactation or multiple lactations (Poppe et al., 2021), which explains the higher heritability of LnVar and $r_{\text {auto }}$. Another disadvantage of using response traits to only a single disturbance per cow, is that for some types of disturbances or extremely severe disturbances the best approach may be to decrease milk yield severely instead of only by a little, to preserve health and resilience later in life (Friggens et al., 2017; Knap and Doeschl-Wilson, 2020). In those cases, cows may be classified as resilient if they did not show a response but showed reduced resilience in the remaining lactation or later lactations. LnVar and $\mathrm{r}_{\text {auto }}$ summarize response to all disturbances throughout the entire lactation or multiple lactations (Poppe et al., 2021) and therefore generate a more complete picture of the overall resilience of the cow than response to a single disturbance. A reason not to select for the response traits to the heat wave in particular, is that in this study we were interested in breeding for general resilience to a broad range of disturbances, not only a single type of disturbance. Studying single types of disturbances is suitable for investigating physiological mechanisms underlying resilience or developing models, as performed for nutritional challenges in dairy cows (Codrea et al., 2011; Bjerre-Harpøth et al., 2012) and goats (Friggens et al., 2016), and for weaning in piglets (Revilla et al., 2019). If the desire is to select for heat tolerance, alternative approaches may be more direct (Carabaño et al., 2019). In summary, the response traits to the herd disturbance and heat wave are not the best option for breeding for general resilience themselves but do confirm that LnVar and $r_{\text {auto }}$ contain information about resilience.

Natural log-transformed variance has a strong positive genetic correlation with milk yield level, which was considered to be partly due to a statistical scale effect, where variance increases with the mean (Falconer and Mackay, 1996; Poppe et al., 2020). Results from this study show that not only LnVar, but also depth of the decrease, total yield loss, and average yield loss per day were unfavorably genetically correlated with ADMY. Similarly, milk yield level before a nutritional challenge has been found to be related to the strength of response in milk yield in dairy cattle (Codrea et al., 2011; BjerreHarpøth et al., 2012) and goats (Friggens et al., 2016). In addition, highly productive cows tend to have a stronger response in milk yield to heat stress than cows 
with low production (Bernabucci et al., 2010; Carabaño et al., 2019). These observations suggest that for highly productive cows, milk yield is not only more variable due to scale effect, but also for an important part due to higher vulnerability. Nevertheless, partial genetic correlations between LnVar and the response traits to the disturbances suggest that among cows with the same milk yield level, low LnVar is associated with a weaker milk yield response. This makes it possible to breed for better resilience using LnVar without comprising milk yield level. The unfavorable genetic correlation between LnVar and milk yield was lower than unity. Therefore, by including both LnVar and milk yield in the breeding goal with appropriate weights, both traits can be improved simultaneously.

Both LnVar and $r_{\text {auto }}$ contain information about resilience, but the question remains if and how they should be applied in the breeding goal. Natural logtransformed variance clearly has an economic value because of its associations with yield loss upon disturbances. However, double-counting should be avoided when assigning an economic value based on yield loss (Berghof et al., 2019b), because yield loss to some types of disturbances, such as mastitis (Huijps et al., 2008; Halasa et al., 2009), is already accounted for by the economic values of other breeding goal traits. For $\mathrm{r}_{\text {auto }}$ it is less clear than for LnVar that it has an economic value, because it was not associated with total yield loss after disturbances. In addition, $\mathrm{r}_{\text {auto }}$ had only weak genetic correlations with health traits and longevity (Poppe et al., 2020), which suggests that $r_{\text {auto }}$ is also not particularly informative about disease resistance and is not related to the productive lifespan of a cow. Although $r_{\text {auto }}$ seems therefore not directly economically useful, its clear association with recovery time poses an important advantage. Quick recovery is beneficial for animal welfare (Berghof et al., 2019b), and may also lead to less medicine use and labor requirements. As far as known, recovery from disturbances is not directly covered by current breeding indices, although we may be selecting indirectly for improved recovery rate to mastitis due to its favorable genetic correlation with SCC (de Haas et al., 2008; Urioste et al., 2012) and mastitis susceptibility (Welderufael et al., 2017). In summary, LnVar and $\mathrm{r}_{\text {auto }}$ are complementary, and both are needed in the breeding goal to genetically improve all aspects of resilience.

\section{CONCLUSIONS}

This study shows that LnVar and $r_{\text {auto }}$ were genetically very similar traits in recent and earlier daughter groups from nonoverlapping herd-year-season classes. Therefore, improvement of these traits is expected to be observed in next generations upon genetic selection. Furthermore, daughters of sires with low EBV for LnVar had weaker response in milk yield to a heat wave and disturbances at herd level than daughters of sires with high EBV. Daughters of sires with low EBV for $r_{\text {auto }}$ had quicker recovery from disturbances than daughters of sires with high EBV. These results confirm that both LnVar and $r_{\text {auto }}$ are informative about resilience, and they cover different aspects. Therefore, both traits should be combined in a resilience index to improve all resilience aspects simultaneously.

\section{ACKNOWLEDGMENTS}

We acknowledge the Dutch Ministry of Economic Affairs (The Hague, the Netherlands; TKI Agri \& Food project 16022) and the Breed4Food partners Cobb Europe (Boxmeer, the Netherlands), CRV (Arnhem, the Netherlands), Hendrix Genetics (Boxmeer, the Netherlands) and Topigs Norsvin (Beuningen, the Netherlands) for their financial support. In addition, we acknowledge the European Union's Horizon 2020 research and innovation program (GenTORE) under grant agreement no. 727213 for its financial support. Furthermore, we acknowledge Cooperation CRV and CRV BV (Arnhem, the Netherlands) for providing the data. Finally, we acknowledge the Breed4Food partners and Cooperation CRV and CRV BV for their help in interpreting the results. The authors have not stated any conflicts of interest.

\section{REFERENCES}

Aho, A. V., B. W. Kernighan, and P. J. Weinberger. 1988. The AWK Programming Language. Addison-Wesley Publishing Company.

Berghof, T. V. L., H. Bovenhuis, and H. A. Mulder. 2019a. Body weight deviations as indicator for resilience in layer chickens. Front. Genet. 10:1216. https://doi.org/10.3389/fgene.2019.01216.

Berghof, T. V. L., M. Poppe, and H. A. Mulder. 2019b. Opportunities to improve resilience in animal breeding programs. Front. Genet. 9:692. https://doi.org/10.3389/fgene.2018.00692.

Bernabucci, U., N. Lacetera, L. H. Baumgard, R. P. Rhoads, B. Ronchi, and A. Nardone. 2010. Metabolic and hormonal acclimation to heat stress in domesticated ruminants. Animal 4:1167-1183. https: //doi.org/10.1017/S175173111000090X.

Bjerre-Harpøth, V., N. C. Friggens, V. M. Thorup, T. Larsen, B. M. Damgaard, K. L. Ingvartsen, and K. M. Moyes. 2012. Metabolic and production profiles of dairy cows in response to decreased nutrient density to increase physiological imbalance at different stages of lactation. J. Dairy Sci. 95:2362-2380. https://doi.org/10 $.3168 /$ jds.2011-4419.

Bohmanova, J., I. Misztal, S. Tsuruta, H. D. Norman, and T. J. Lawlor. 2008. Short communication: Genotype by environment interaction due to heat stress. J. Dairy Sci. 91:840-846. https://doi .org/10.3168/jds.2006-142.

Calus, M. P. L. 2006. Estimation of genotype $\times$ environment interaction for yield, health and fertility in dairy cattle. $\mathrm{PhD}$ thesis. Wageningen University, Wageningen, the Netherlands.

Carabaño, M. J., M. Ramón, A. Menéndez-Buxadera, A. Molina, and C. Díaz. 2019. Selecting for heat tolerance. Anim. Front. 9:62-68. https://doi.org/10.1093/af/vfy033. 
Cheng, J., A. M. Putz, J. C. S. Harding, M. K. Dyck, F. Fortin, G. S. Plastow, PigGen Canada, and J. C. M. Dekkers. 2020. Genetic analysis of disease resilience in wean-to-finish pigs from a natural disease challenge model. J. Anim. Sci. https://doi.org/10.1093/ jas/skaa244.

Codrea, M. C., S. Højsgaard, and N. C. Friggens. 2011. Differential smoothing of time-series measurements to identify disturbances in performance and quantify animal response characteristics: An example using milk yield profiles in dairy cows. J. Anim. Sci. 89:3089-3098. https://doi.org/10.2527/jas.2010-3753.

Colditz, I. G., and B. C. Hine. 2016. Resilience in farm animals: Biology, management, breeding and implications for animal welfare. Anim. Prod. Sci. 56:1961-1983. https://doi.org/10.1071/AN15297.

CRV. 2018. E-7 Breeding value estimation of milk production traits with test-day model. Accessed Oct. 10, 2020. https://cooperatiecrv-be6.kxcdn.com/wp-content/uploads/2018/10/E07-tdm-apr2018EN.pdf.

de Haas, Y., W. Ouweltjes, J. ten Napel, J. J. Windig, and G. de Jong. 2008. Alternative somatic cell count traits as mastitis indicators for genetic selection. J. Dairy Sci. 91:2501-2511. https://doi.org/ 10.3168/jds.2007-0459.

Falconer, D. S., and T. F. C. Mackay. 1996. Introduction to Quantitative Genetics. 4th ed. Pearson Education Limited.

Friggens, N. C., F. Blanc, D. P. Berry, and L. Puillet. 2017. Review: Deciphering animal robustness. A synthesis to facilitate its use in livestock breeding and management. Animal 11:2237-2251. https: //doi.org/10.1017/S175173111700088X.

Friggens, N. C., C. Duvaux-Ponter, M. P. Etienne, T. Mary-Huard, and P. Schmidely. 2016. Characterizing individual differences in animal responses to a nutritional challenge: Toward improved robustness measures. J. Dairy Sci. 99:2704-2718. https://doi.org/10 $.3168 /$ jds.2015-10162.

Gilmour, A. R., B. J. Gogel, B. R. Cullis, S. J. Welham, and R. Thompson. 2015. ASReml user guide release 4.1 functional specification. VSN International Ltd.

Halasa, T., M. Nielen, A. P. W. De Roos, R. Van Hoorne, G. De Jong, T. J. G. M. Lam, T. Van Werven, and H. Hogeveen. 2009. Production loss due to new subclinical mastitis in Dutch dairy cows estimated with a test-day model. J. Dairy Sci. 92:599-606. https:/ /doi.org/10.3168/jds.2008-1564.

Hayes, B. J., M. Carrick, P. Bowman, and M. E. Goddard. 2003. Genotype $\times$ environment interaction for milk production of daughters of Australian dairy sires from test-day records. J. Dairy Sci. 86:3736-3744. https://doi.org/10.3168/jds.S0022-0302(03)73980 $-0$.

Huijps, K., T. J. G. M. Lam, and H. Hogeveen. 2008. Costs of mastitis: Facts and perception. J. Dairy Res. 75:113-120. https://doi.org/10 $.1017 /$ S0022029907002932.

Knap, P. W., and A. Doeschl-Wilson. 2020. Why breed disease-resilient livestock, and how? Genet. Sel. Evol. 52:60. https://doi.org/ 10.1186/s12711-020-00580-4.

KNMI. 2019. Klimatologie: Daggegevens van het weer in Nederland - Download. Accessed Oct. 9, 2019. http://projects.knmi.nl/ klimatologie/daggegevens/selectie.cgi.

Koenker, R. 2005. Quantile regression. Econometric Society Monographs. A. Prat and S. Bonhomme, ed. Cambridge University Press.

Koenker, R. 2018. quantreg: Quantile Regression. R package version 5.36. https://CRAN.R-project.org $/$ package=quantreg.
Mäntysaari, E. A., Z. Liu, and P. VanRaden. 2010. Interbull validation test for genomic evaluations. Interbull Bull. 41:17-22. https:/ /journal.interbull.org/index.php/ib/article/view/1134.

National Research Council. 1971. A Guide to Environmental Research on Animals. Natl. Acad. Sci.

Ødegård, J., G. Klemetsdal, and B. Heringstad. 2003. Genetic improvement of mastitis resistance: Validation of somatic cell score and clinical mastitis as selection criteria. J. Dairy Sci. 86:41294136. https://doi.org/10.3168/jds.S0022-0302(03)74027-2.

Poppe, M., G. Bonekamp, M. L. van Pelt, and H. A. Mulder. 2021. Genetic analysis of resilience indicators based on milk yield records in different lactations and at different lactation stages. J. Dairy Sci 104:1967-1981. https://doi.org/10.3168/jds.2020-19245.

Poppe, M., R. F. Veerkamp, M. L. van Pelt, and H. A. Mulder. 2020. Exploration of variance, autocorrelation, and skewness of deviations from lactation curves as resilience indicators for breeding. J. Dairy Sci. 103:1667-1684. https://doi.org/10.3168/jds.2019-17290.

Putz, A. M., J. C. S. Harding, M. K. Dyck, F. Fortin, G. S. Plastow, and J. C. M. Dekkers. 2019. Novel resilience phenotypes using feed intake data from a natural disease challenge model in weanto-finish pigs. Front. Genet. 9:660. https://doi.org/10.3389/fgene .2018.00660.

Ravagnolo, O., I. Misztal, and G. Hoogenboom. 2000. Genetic component of heat stress in dairy cattle, development of heat index function. J. Dairy Sci. 83:2120-2125. https://doi.org/10.3168/jds .S0022-0302(00)75094-6.

Revilla, M., N. C. Friggens, L. P. Broudiscou, G. Lemonnier, F. Blanc, L. Ravon, M. J. Mercat, Y. Billon, C. Rogel-Gaillard, N. Le Floch, J. Estellé, and R. Muñoz-Tamayo. 2019. Towards the quantitative characterisation of piglets' robustness to weaning: A modelling approach. Animal 13:2536-2546. https://doi.org/10.1017/ S1751731119000843.

Scheffer, M. 2009. Critical Transitions in Nature and Society. Princeton University Press.

Scheffer, M., J. E. Bolhuis, D. Borsboom, T. G. Buchman, S. M. W. Gijzel, D. Goulson, J. E. Kammenga, B. Kemp, I. A. van de Leemput, S. Levin, C. M. Martin, R. J. F. Melis, E. H. van Nes, L. M. Romero, and M. G. M. Olde Rikkert. 2018. Quantifying resilience of humans and other animals. Proc. Natl. Acad. Sci. USA 115:11883-11890. https://doi.org/10.1073/pnas.1810630115.

Urioste, J. I., J. Franzén, J. J. Windig, and E. Strandberg. 2012. Genetic relationships among mastitis and alternative somatic cell count traits in the first 3 lactations of Swedish Holsteins. J. Dairy Sci. 95:3428-3434. https://doi.org/10.3168/jds.2011-4739.

van Pelt, M. 2017. Genetic improvement of longevity in dairy cows. $\mathrm{PhD}$ thesis. Wageningen University, Wageningen, the Netherlands.

Welderufael, B. G., L. L. G. Janss, D. J. de Koning, L. P. Sørensen, P. Løvendahl, and W. F. Fikse. 2017. Bivariate threshold models for genetic evaluation of susceptibility to and ability to recover from mastitis in Danish Holstein cows. J. Dairy Sci. 100:4706-4720. https://doi.org/10.3168/jds.2016-11894.

\section{ORCIDS}

M. Poppe ๑ https://orcid.org/0000-0001-7801-3942

H. A. Mulder @ https://orcid.org/0000-0003-2124-4787

R. F. Veerkamp 이 https://orcid.org/0000-0002-5240-6534 